\title{
CANADIAN ANAESTHETISTS’ SOCIETY PRIZE
}

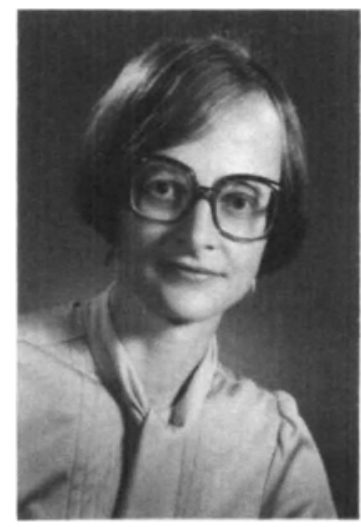

Dr. BeverLey BritT

The Canadian Anaesthetists' Society Prize for 1977 was awarded to Dr. Beverley Britt of the University of Toronto for her paper with L. Endrenyi, W. Kalow, and P.L. Peters: The adenosine triphosphate (ATP) depletion test: comparison with the caffeine contracture test as a method of diagnosing malignant hyperthermia susceptibility. Canadian Anaesthetists' Society Journal 23: 624-635 (November, 1976).

\section{PRIX ANNUEL DE LA SOCIETE CANADIENNE DES ANESTHESISTES}

\section{Docteur Beverley Britt}

Le prix annuel de la Société Canadienne des Anesthésistes pour 1976 a été attribué au docteur Beverley Britt de l'Université de Toronto pour son travail en collaboration avec L. Endrenyi, W. Kalow et.P.L. Peters, intitulé: "Le test de l'épuisement en adénosine triphosphate (ATP): comparaison avec le test à la caféine comme méthode de détection de la susceptibilité à l'hyperthermie maligne," Journal de la Société Canadienne des Anesthésistes, vol. 23, p. 624-635, novembre 1976. 